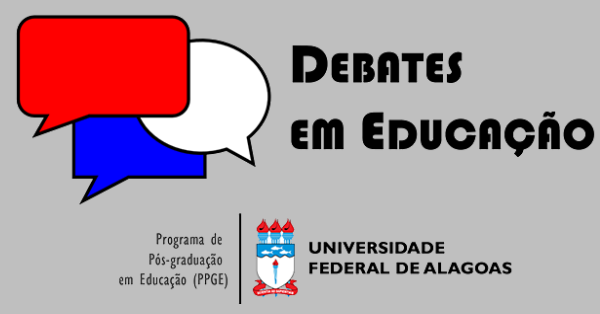

ISSN Eletrônico 2175-6600

Vol. 13 I Número Especial I 2021

Maria de Fátima Gomes da Silva

Universidade de Pernambuco fatimamaria18@gmail.com

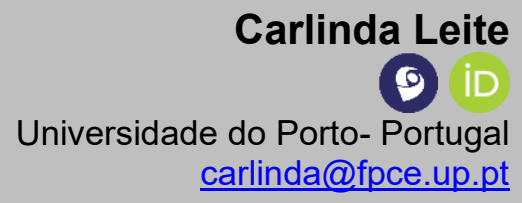

carlinda@fpce.up.pt

\section{CONSTRUÇÃO DE CONHECIMENTOS NA EDUCAÇÃO SUPERIOR SOB A ÉGIDE DA INTERDISCIPLINARIDADE: QUE POSSIBILIDADES?}

\section{RESUMO}

Este artigo apresenta resultados de uma investigação de pósdoutoramento que teve por objetivo analisar o modo como a interdisciplinaridade está presente nas práticas docentes da Educação Superior em Portugal e no Brasil. O estudo recorreu a uma abordagem de orientação qualitativa, em que a coleta de dados foi feita por um questionário de pergunta aberta. Os dados foram analisados por meio da técnica de Análise de Conteúdo. Concluiu-se que, embora essa construção de conhecimento na docência universitária se perspective no sentido da interdisciplinaridade, a mesma apresenta uma visão cartesiana e simplista. Por isso, tornam-se relevantes práticas docentes universitárias na perspectiva de uma epistemologia da interdisciplinaridade, com base no diálogo, na parceria e no rigor científico.

Palavras-chave: Interdisciplinaridade. Prática Docente. Educação Superior.

\section{CONSTRUCTION OF KNOWLEDGE IN HIGHER EDUCATION UNDER THE AEGIS OF INTERDISCIPLINARITY: WHAT ARE THE POSSIBILITIES?}

\section{ABSTRACT}

This article presents the results of a post-doctoral investigation that aimed to analyze how interdisciplinarity is present in Higher Education teaching practices in Portugal and Brazil. The study used a qualitative approach, in which data collection was performed using an open-ended questionnaire. Data were analyzed through the Content Analysis technique. We concluded that, although this construction of knowledge in university teaching has an interdisciplinary perspective, it presents a cartesian and simplistic view. Therefore, university teaching practices become relevant from the perspective of an epistemology of interdisciplinarity, based on dialogue, partnership and scientific rigor.

Keywords: Interdisciplinarity. Teaching Practice. Higher education.

Submetido em: 10/05/2021

Aceito em: 11/06/2021

Publicado em: 29/09/2021

do https://doi.org/10.28998/2175-6600.2021v13nEspp392-405 


\section{INTRODUÇÃO}

O atual cenário da educação superior aponta para que as práticas docentes se orientem no sentido da interdisciplinaridade. Assim, os professores precisam repensar as suas práticas docentes, de modo a romper com rotinas monodisciplinares. Na visão de Santana e Silva (2016), investigações sobre essa temática constituem uma necessidade emergente, pois as transformações que ocorrem no atual contexto socioeducacional exigem a formação de sujeitos políticos, com esses conhecimentos para atuarem na sociedade complexa em que estão inseridos.

Segundo Fazenda (2011, p.51), “[...] a interdisciplinaridade caracteriza-se pela intensidade das trocas entre os especialistas e pelo grau de integração real das disciplinas no interior de um mesmo projeto de pesquisa". Com base nessas ideias de Fazenda, considera-se que a construção de conhecimentos na educação superior deve ser materializada como um processo de colaboração entre disciplinas e setores heterogêneos, caracterizada por uma reciprocidade entre docentes e discentes. Tendo por base esta temática, este texto tem por objetivo apresentar os resultados de uma pesquisa de pós-doutoramento que investigou o modo como está presente a interdisciplinaridade na educação superior em Portugal e no Brasil.

$\mathrm{Na}$ sua estrutura, para além desta introdução, na revisão de literatura reflete-se sobre a problemática da hiperespecialização do conhecimento e sobre as possibilidades de vivência de uma epistemologia da interdisciplinaridade ${ }^{1}$ na docência universitária à luz da totalidade, a qual consiste numa categoria epistêmica deste modo de construção do conhecimento (SILVA, 2009). Em seguida, são apresentados os procedimentos metodológicos. Na apresentação e discussão dos resultados, procede-se a uma análise sobre a opinião de docentes universitários a respeito do modo como está presente a interdisciplinaridade na educação superior em Portugal e no Brasil. Por fim, apresentamse as conclusões, recordando o objetivo que orientou este estudo e enfatizando a necessidade de que as práticas docentes universitárias sejam norteadas pela perspectiva que orienta o estudo.

\footnotetext{
1 O termo "epistemologia da interdisciplinaridade", na docência universitária, quer referir a vivência de uma práxis (teoria e prática), que se materializa por meio da categoria interdisciplinar totalidade, e que poderá possibilitar o diálogo entre diversas disciplinas e a construção do conhecimento como um todo, sem fragmentações. A categoria totalidade, no que refere à interdisciplinaridade na docência universitária, implica uma prática docente cuidadosa no aspecto histórico da sociedade, dentro do qual se constrói o conhecimento. Aponta para uma atitude de superação de toda e qualquer visão fragmentada que ainda se mantém muitas vezes presente na universidade. Uma epistemologia interdisciplinar com base na totalidade possibilita a (re)construção do conhecimento frente à fragmentação do saber.
} 


\section{REVISÃO BIBLIOGRÁFICA}

\subsection{Sobre a interdisciplinaridade}

Esta seção está subdividida em duas subseções. Reflete-se, primeiramente, sobre interdisciplinaridade como uma barreira à hiperespecialização do conhecimento, ressaltando que a especialização que se fecha em si mesma, fragmenta a realidade e impede docentes e discentes de conceberem o global. Seguidamente consideram-se as possibilidades de vivência de uma epistemologia da interdisciplinaridade na educação superior à luz da categoria totalidade.

\section{1. $1 \mathrm{~A}$ interdisciplinaridade como barreira à hiperespecialização do conhecimento}

Neste subitem deste artigo considera-se a possibilidade de se pensar a resolução de problemas relativos à fragmentação do conhecimento, por meio da interdisciplinaridade. Para isso, recorre-se, inicialmente, a Gusdorf (2006), quando este na caracterização de uma possível epistemologia da interdisciplinaridade nas práticas docentes da Educação Superior aponta que,

[...] a interdisciplinaridade aparece como um método filosófico por excelência: não um devaneio anexo à margem da investigação principal, como acontece com certos especialistas, que tomam consciência das lacunas e insuficiências da sua especialização tarde demais, mas antes o grande eixo de um pensamento empenhado em reagrupar todos os testemunhos do homem sobre o homem disperso pela diversidade dos espaços-tempos-culturais (GUSDORF, 2006, p. 19).

Dessa tese ressaltam-se, pelo menos, três ideias-chave que sinalizam, de forma latente, para a indissociável relação entre a interdisciplinaridade e a educação superior. Elas são: a interdisciplinaridade enquanto método filosófico por excelência; as lacunas e insuficiências da especialização; e a importância de um pensamento que esteja preocupado em reagrupar todos os testemunhos da pessoa humana dispersos pela diversidade dos espaços-tempos-culturais.

Nessa perspectiva, pode-se afirmar que compreender e vivenciar a construção de conhecimentos na educação superior sob a égide da interdisciplinaridade significa percebê-la na sua relação com a investigação científica. Assim, convém considerar que a construção de conhecimentos nesse nível de ensino jamais poderá prescindir da investigação científica. 
Em contrapartida, para se pensar a construção de conhecimentos na educação superior, por meio da interdisciplinaridade, considerando-a como um método por excelência, é também necessário levar em consideração a segunda categoria apreendida no discurso de Gusdorf (2006), associada às lacunas da especialização ou, em outras palavras, aos efeitos nocivos da hiperespecialização do conhecimento. Silva (2009) se refere às lacunas da especialização afirmando que, através destas, há um confinamento dos sujeitos "especialistas" e o despedaçamento do saber que incidiu de certo modo no que Morin (2001) denominou de "ignorância e cegueira". O reconhecimento dos efeitos nocivos da fragmentação do conhecimento justifica a postura de "juntar especialistas", a fim de realizarem um projeto interdisciplinar de trabalho. A hiperespecialização do saber, que se fecha em si mesma, pode criar obstáculos se o especialista for aquela figura que, por possuir uma visão determinante, quantitativa e formalista, ignorar e ocultar todo o processo histórico dos fatos sociais e não questionar as razões reais e objetivas da problemática social e do porquê de um conhecimento reproduzido em parcelas.

Em síntese, no quadro dessas ideias, vislumbra-se a interdisciplinaridade como uma possibilidade de resolver problemas relativos à fragmentação do conhecimento, com base nas ações parcelizadas de sujeitos justapostos que tentam "defender", a seu modo, cada um à luz de uma perspectiva particular, problemas sociais e educacionais caóticos. Nesse sentido, Lima e Ramos (2017, p. 165) afirmam que,

[...] a interdisciplinaridade evidencia a necessidade de identificação das múltiplas perspectivas constituintes de um fenômeno/acontecimento, ensejando maior ligação, maior vínculo, entre os saberes das distintas áreas de conhecimento.

Nesse caso, a interdisciplinaridade sinalizaria para soluções mais qualificadas e para a problemática da fragmentação do conhecimento.

A terceira categoria identificada na teoria de Gusdorf (2006), anteriormente mencionada, concerne à importância de um pensamento que esteja preocupado em reagrupar todos os testemunhos do homem, o que nos remete para o que Morin (1990, p. 18) chama de "[...] o império de disjunção, de redução e de abstração cujo conjunto constitui [...] o 'paradigma da simplificação' [...]". Assim, o "império" da disjunção torna rara a comunicação entre o conhecimento científico e a reflexão filosófica, simplificando o pensamento e tornando o conhecimento fragmentado.

Em face dessa visão simplificadora e unidimensional, o sujeito se torna incapaz de conceber a complexidade dos fatos sociais e do conhecimento, ou seja, para Morin (1990), o sujeito que desconhece e/ou desconsidera a realidade antropossocial na sua 
microdimensão (o ser individual) e na sua macrodimensão (o conjunto planetário da Humanidade) não poderá vivenciar o conhecimento de forma complexa. Para se pensar o conhecimento interdisciplinarmente se faz necessário trabalhar o paradoxo do uno e do múltiplo em termos da construção dos saberes.

Em outras palavras, é possível compreender que vivenciar a interdisciplinaridade na educação superior implica uma conjugação de esforços no sentido de distinguir sem separar e associar sem identificar, ou reduzir através do princípio dialógico (MORIN,1990). Numa situação contrária a essa, poderá haver simplificação do objeto ou divisão deste em partes e/ou fragmentos que são conduzidos por especialistas de áreas diversas, sem haver, sequer, uma intercomunicação entre eles. Sob essa perspectiva de conceber o complexus e/ou a complexidade do pensamento humano, há que ter presente que nas práticas docentes da educação superior a interdisciplinaridade deverá constituir atenção principal entre os que a investigam e os que a desejam praticar.

Para Souza; Bussolotti; Cunha e Fazenda (2020, p. 106),

a interdisciplinaridade se constitui, assim, por uma ação que se realiza entre as disciplinas envolvidas, no que diz respeito às possibilidades de intersecção entre elas. Não se trata de juntar uma disciplina à outra, mas de compreender quais são - ou onde estão - os pontos de convergência e/ou de complementaridade.

$\mathrm{Na}$ lógica do que referem as autoras supracitadas, para vivenciar práticas docentes na perspectiva da interdisciplinaridade, o professor vai necessitar, também, dessa compreensão. Ou seja, de que se faz necessário essa intersecção entre as disciplinas, por meio de um movimento dialógico que dê conta de identificar pontos de convergência e/ou de complementaridade. Ainda a esse respeito, Perin e Malavasi (2020, p. 145) afirmam que "o vínculo entre as disciplinas, sem anular a essência de cada uma, denota uma comunicação entre os saberes diferente da que normalmente habituamo-nos [...]". Essa assertiva reforça a ideia de imprescindibilidade de cruzamento entre as disciplinas, e alerta para a importância de que os docentes universitários repensem as suas práticas de forma a concebê-las e geri-las sob o a égide da interdisciplinaridade.

No quadro dessas ideias Fazenda (1999, p. 18), afirma que uma atitude interdisciplinar é caracterizada pela "[...] ousadia, é a transformação da insegurança num exercício do pensar, num construir [...]". Essas reflexões aqui fomentadas permitem sinalizam para infinitas possibilidades da interdisciplinaridade, pois esta permite o rompimento com as fronteiras das disciplinas por meio da diversidade e da criatividade, embora não negue as especialidades e a importância de cada ciência. Nesse sentido, Roggero (2010, p. 139) concebe "[...] a universidade como o locus natural para que a 
interdisciplinaridade ocorra, uma vez que é o lugar onde se constrói, se organiza e se distribui conhecimento [...]".

Pode-se dizer que à universidade compete produzir conhecimento sobre a importância de nas práticas docentes universitárias se propiciar o debate e a intervenção interdisciplinares, de forma a possibilitar a construção do conhecimento em totalidade. Assim, se faz necessário superar as barreiras da simplificação e conceber o conhecimento nas suas múltiplas determinações e mediações históricas, sem fragmentálo.

Ainda na esfera dessas reflexões, vale recordar o pensamento de Lima; Cassimiro e Rabelo (2020, p. 126), ao sustentarem que,

é necessária a abertura de um caminho efetivo para se trabalhar de forma interdisciplinar, para que ela não seja apenas uma utopia, mas sim uma realidade, em que desenvolver um conteúdo se torne muito mais do que apenas transmitir ou repassar determinado assunto; que as disciplinas se completem e não se distanciem, mantendo suas singularidades e desenvolvendo no educando o interesse em participar desse processo de aprendizagem.

As ideias acima referidas reiteram a importância de vivência da interdisciplinaridade como um movimento dialógico, em que as disciplinas se complementam, mas mantém a singularidade. Possibilita pensar na relação entre os saberes de forma dinâmica e interativa. Essa vivência propicia a construção do conhecimento de forma ampla e, assim, rompe com a divisão entre disciplinas, sem ocultar a especificidade de cada uma. De fato, o conhecimento não pode se processar em campos fechados e isolados. Por essa razão, recorre-se a Gusdorf (2006, p. 26), quando afirma que "a exigência interdisciplinar impõe a cada especialista que transcenda sua própria especialidade, tomando consciência de seus próprios limites para colher as contribuições das outras disciplinas"

Fazenda (1999, p. 18), afirma que uma atitude interdisciplinar é caracterizada pela "[...] ousadia, é a transformação da insegurança num exercício do pensar, num construir [...]". Essas reflexões oportunizam a sinalização para infinitas possibilidades da interdisciplinaridade, uma vez que por seu intermédio dá-se o rompimento com as fronteiras das disciplinas por meio da diversidade e da criatividade, embora não negue as especialidades e a importância de cada ciência. Nesse sentido, Roggero (2010, p. 139) concebe "[...] a universidade como o locus natural para que a interdisciplinaridade ocorra, uma vez que é o lugar onde se constrói, se organiza e se distribui conhecimento [...]".

Em síntese pode-se dizer que à universidade compete produzir conhecimento sobre a importância de nas práticas docentes universitárias se proporcionar o debate e a intervenção interdisciplinares, de forma a possibilitar a construção do conhecimento em 
totalidade. Ou seja, se faz necessário superar as barreiras da simplificação e conceber o conhecimento nas suas múltiplas determinações e mediações históricas, sem fragmentálo.

2.2.2 Possibilidades de vivência de uma epistemologia da interdisciplinaridade no Ensino Superior à luz da totalidade

Neste subitem reflete-se sobre uma das categorias mestras do pensamento interdisciplinar, a totalidade (SILVA, 2009). É no quadro dessa categoria que se apresentam as reflexões a seguir. A totalidade com relação à interdisciplinaridade implica muita atenção e cuidado ao aspecto histórico da sociedade, dentro do qual se constroem o conhecimento e as práticas educativas. Aponta para uma atitude de superação de toda e qualquer visão fragmentada e/ou dicotomia que existir, neste caso, na universidade. Para Jantsch e Bianchetti (2011, p. 27),

Delimitar um objeto para investigação não é fragmentá-lo, ou limitá-lo arbitrariamente. Ou seja, se o processo de conhecimento nos impõe a delimitação de determinado problema, isto não significa que tenhamos que abandonar as múltiplas determinações que o constituem. E, neste sentido, mesmo delimitado, um fato teima em não perder o tecido da totalidade de que faz parte indissociável.

Com efeito, a fragmentação ou disciplinarização do conhecimento em ramos específicos constitui uma realidade e uma necessidade para o ser humano com a qual ele se defronta. No entanto, a delimitação de um objeto de estudo na esfera da construção do conhecimento nas práticas docentes universitárias não deverá constituir para o docente o abandono de sua totalidade. Nessa perspectiva, entra em cena a interdisciplinaridade, uma vez que, diante da necessidade de não perder de vista a totalidade do objeto delimitado para estudo, os sujeitos interdisciplinarmente constituídos deverão atuar, considerando as suas múltiplas dimensões.

Desse modo, práticas docentes universitárias que vislumbrem a possibilidade de se nortearem por essa orientação metodológica implicam encontro, troca, parceria, diálogo, mas também vivência criativa. Para isso, o docente não deve abrir mão do rigor, mas ousar e buscar o novo através da ampliação e constante revisão de seus princípios e pressupostos. Além disso, será necessário entrar em um processo de flexibilização em relação às fronteiras internas que há entre os sujeitos e entre o próprio conhecimento por eles construído. Essa interação poderá impulsionar os sujeitos a interagirem de maneira mais criativa e flexível. 
Infere-se, pois, que as possibilidades de vivência de uma epistemologia da interdisciplinaridade na educação superior que se ancore na totalidade tem a ver, de certa forma, com as possíveis relações que se possam estabelecer entre os sujeitos historicamente constituídos por meio do diálogo, da parceria e do rigor científico.

\section{METODOLOGIA}

No procedimento de coleta de dados que permitiu conhecer de que modo a interdisciplinaridade está presente em práticas docentes universitárias de Portugal e do Brasil, seguiu-se uma abordagem qualitativa de pesquisa. Essa opção resultou do fato de se considerar, tal como Bogdan e Bilklen (2010), que esta permite uma melhor compreensão da problemática a ser investigada. Este tipo de abordagem possibilita uma compreensão sobre a realidade das pessoas e dos fatos em sua essência. Oliveira (2012, p. 37), entende a "pesquisa qualitativa como sendo um processo de reflexão e análise da realidade [...] em seu contexto histórico e/ou segundo sua estruturação." Ou seja, esse tipo de pesquisa conduz o pesquisador ao cerne do objeto de estudo.

Os sujeitos da pesquisa foram dez docentes universitários, sendo cinco de Portugal e cinco do Brasil, os quais, na análise de dados, são identificados pelas siglas DUP (docente universitário de Portugal) e DUB (docente universitário do Brasil). A coleta de dados foi feita mediante um questionário de perguntas abertas. Esse questionário foi elaborado com o objetivo de que os professores, sujeitos da pesquisa, respondessem de forma livre e fornecessem informações sobre o modo como a interdisciplinaridade se faz presente e está a ser vivenciada nas suas práticas docentes. $O$ interesse em fazer um paralelo comparativo entre Portugal e Brasil, justifica-se pela necessidade de compreender como a interdisciplinaridade tem atravessado a prática docente de professores universitários nesses dois países que, embora tenham sistemas educativos diferentes, têm afinidades e pontos em comum em relação a essa temática.

A análise dos dados foi realizada por meio da técnica de Análise de Conteúdo temático-categorial (BARDIN, 2014), a qual passou pelas seguintes fases: organização do material; codificação; categorização; tratamento dos resultados obtidos e interpretação. 


\section{RESULTADOS E DISCUSSÃO}

\subsection{Interdisciplinaridade nas práticas docentes universitárias: o que dizem os professores.}

Como já foi referido, o estudo teve como objetivo conhecer a opinião de docentes universitários de Portugal e do Brasil sobre o modo como a interdisciplinaridade se fazia presente em suas práticas. Por isso, e como também já foi mencionado, considerou-se necessário seguir um caminho de orientação compreensiva que permitisse apreender os sentidos atribuídos, por esses sujeitos, à interdisciplinaridade. Para tanto, cada um foi contatado pessoalmente e foi-lhe pedido que exprimisse a sua opinião, respondendo a um questionário de perguntas abertas, o qual indagou sobre modo como a interdisciplinaridade se fazia presente nas suas práticas docentes e, se consideravam que ela estava sendo vivenciada na educação superior. Os dados referentes a essas respostas foram tratados pela técnica da Análise de Conteúdo (BARDIN, 2014), a qual permitiu identificar categorias de sentidos que orientaram a análise.

No caso dos docentes universitários do Brasil (DUB) foi sinalizada a existência de possibilidades de vivência da interdisciplinaridade nas práticas docentes universitárias, expressa em opiniões como as seguintes:

Participei em 2006 de um projeto multidisciplinar em que todos os docentes de uma mesma turma trabalharam em conjunto, utilizando a internet para nos correspondermos (DUB1).

Orientei trabalhos de final de curso ligados à educação que faziam pontes com áreas, tais como: psicologia e saúde. Os objetivos destes trabalhos eram associar questões relacionadas à educação com aspectos psicológicos (DUB2).

Sim, [...] coordenei pessoalmente uma jornada pedagógica que teve como objetivo envolver os diversos alunos e professores de vários departamentos sobre temas voltados para a educação e formação de educadores (DUB3).

[...] eu venho articulando a disciplina Metodologia da Pesquisa Educacional com os conteúdos das disciplinas Pesquisa e Prática Pedagógica, inclusive ao final de cada semestre temos os Seminários Integradores que têm a finalidade de apresentar como se deu a integração entre as disciplinas (DUB4).

Um evento, de apenas um dia, com alguns painéis de apresentação e discussões entre os presentes, sobre avaliação do Ensino Superior. 
Considerei-o interdisciplinar por abordar a questão da avaliação do ensino para qualquer área do conhecimento (DUB5).

Ressalta-se que, embora tenha sido adotado o termo educação superior, preservou-se o termo "ensino superior" proferido pelos sujeitos da pesquisa em suas respostas. No entanto, para a análise interpretativa dos dados, e por corresponder ao conceito das autoras, é utilizado o termo educação superior.

Ao sinalizarem as possibilidades de construção de conhecimentos na educação superior sob a égide da interdisciplinaridade, esses docentes percebem que ela existe por meio do trabalho em equipe, da associação de temas e da articulação entre as unidades curriculares. Nesse sentido, pode-se referir que, de fato, o trabalho interdisciplinar na universidade deverá reagrupar o conhecimento de docentes e discentes para tentar evitar a fragmentação do conhecimento que torna o pensamento simplificador, o qual "[...] é incapaz de conceber a conjunção de uno e do múltiplo (unitas multiplex): ou ainda unifica abstratamente ao anular a diversidade sem conceber a unidade" (MORIN, 1990, p. 18).

Os docentes investigados parecem vislumbrar possibilidades de construção de conhecimentos com base no trabalho em equipe, na associação de temas e na articulação entre as unidades curriculares. Infere-se, pois, que estes possivelmente perseguirão nesse intento a ideia de totalidade na construção de conhecimentos por meio do encontro, da socialização do conhecimento, da parceria e do diálogo, mas, também, pela vivência criativa e solitária, a qual é inerente ao movimento interdisciplinar, uma vez que o sujeito interdisciplinar é uno e múltiplo, isto é, individual e coletivo. Além disso, esses docentes sinalizam para uma compreensão de que será outros conhecimentos advindos de outros sujeitos, num processo de flexibilização quanto às fronteiras internas que há entre os sujeitos e entre o próprio conhecimento por eles construído, por meio de uma interação de maneira mais criativa e flexível.

Com relação às respostas dos docentes universitários de Portugal (DUP), foram obtidas as seguintes opiniões:

Nos últimos vinte anos tenho estado empenhado em projectos educacionais (de formação de professores). No entanto, não me recordo de alguma vez ter participado em reuniões (formais ou informais) destinadas a planear abordagens interdisciplinares (DUP1).

Com características de interdisciplinaridade não. Este ano lectivo vou partilhar uma disciplina, ou seja, ela será leccionada por mim e um outro professor. O programa já foi feito por nós, os dois. A Unidade Didáctica é composta por módulos. Ele é de História e eu de Geografia. A disciplina é Aplicações Didácticas nas e das duas disciplinas. Será iniciada em Fevereiro e para além da elaboração do programa ainda não nos sentamos à volta de uma mesa para conversarmos. Temo-nos cruzado no 
corredor, manifestado interesse em nos reunir, mas o trabalho é tanto que não tivemos tempo para marcar uma data. Estou ansiosa por ver como vai funcionar pois trabalhei bem com o outro colega quando da elaboração do programa, apesar de sermos muito diferentes até como pessoas. Mas, penso que, o que irá ocorrer não é interdisciplinaridade (DUP2).

Não posso generalizar considerando que o universo no que tange o ensino superior é muito grande, mas falando a partir de um contexto mais próximo, não considero que essa seja uma preocupação dos que fazem a universidade. Isso não quer dizer que não haja movimentos isolados, solitário que tentam fazer com que o ensino seja mais humanizado e menos tecnicista (DUP3).

Não, mesmo quando presenciei projetos coletivos sendo vivenciados, percebi que os professores reservavam um tempo da aula para tratar do projeto e depois retomavam o trabalho com os conteúdos na mesma abordagem tradicional ou fragmentada do conhecimento o que fazia parecer que o projeto era um apêndice da aula, mas a parte importante era mesmo a do trabalho tradicional com a disciplina específica que cada professor ministrava (DUP4).

[...] De facto, a cultura docente ainda é individualista (injunções da lógica do paradigma produtivista de avaliação) e os professores ainda veem a sua sala de aula como espaço fechado de atuação e a grande quantidade de trabalhos a cumprir individualmente pelo professor e aluno (isso que estou a observar na minha pesquisa). [...]. Desse modo, há nessa experiência a dificuldade dos professores de se tornarem conceptores e gestores do currículo, enfim, de serem artífices da interdisciplinaridade na perspectiva de favorecer uma aprendizagem integrada entre os conhecimentos e práticas (DUP5).

Com base nas opiniões acima enunciadas, foi possível constatar dificuldades dos docentes em promover reuniões que possibilitem o debate sobre a vivência da interdisciplinaridade. Infere-se que tais problemas podem resultar de práticas disciplinares ou monodisciplinares afastadas de uma base teórica interdisciplinar que fundamente a prática. Essa base, segundo Klein (2008), deve ser fundamentada numa pedagogia apropriada, num processo integrador, numa mudança institucional e na relação entre disciplinaridade e interdisciplinaridade

Por meio de uma pedagogia apropriada, docentes e discentes universitários poderão elaborar projetos ou formar grupos de trabalho que favoreçam a colaboração. processo integrador possibilitará "equilíbrio entre amplitude, profundidade e síntese" (KLEIN, 2008, p. 121), admitindo que: a amplitude "assegura uma larga base de conhecimento e informação", a profundidade constitui "o requisito disciplinar, profissional e/ou conhecimento e informação interdisciplinar para a tarefa a ser executada" e a síntese "[...] assegura o processo integrador" (Id., Id.). 
Sobre a mudança institucional, será necessária uma profunda transformação na forma organizacional e institucional da universidade, uma vez que um "ensino interdisciplinar", além de exigir transformações significativas nas propostas curriculares, não poderá prescindir de uma mudança abrangente na organização das instituições no seu todo.

Referente à relação entre disciplinaridade e interdisciplinaridade Klein (2008) considera, ainda, que um projeto interdisciplinar de trabalho deverá incorporar a perspectiva interdisciplinar e disciplinar. Assim, a vivência da interdisciplinaridade não surge para eliminar as disciplinas, mas, para assegurar a inter-relação e a intercomunicação entre os conteúdos, evitando a fragmentação do conhecimento.

\section{CONCLUSÃO}

Como conclusão do estudo, e recordando o objetivo que o orientou, menciona-se que as reflexões aqui apresentadas, e também as respostas dos sujeitos desta pesquisa, apontaram para efeitos nocivos da hiperespecialização do saber, os quais têm na sua origem, principalmente, uma abordagem tradicional ou fragmentada do conhecimento, e correspondem, quer a uma cultura docente individualista, quer à dificuldade que os professores têm de se tornarem gestores do currículo.

Constatou-se que as possibilidades de construção de conhecimentos na educação superior sob a égide da interdisciplinaridade ainda se limitam a ações multidisciplinares, como a organização de eventos com o envolvimento de professores e estudantes, a associação de disciplinas e a elaboração de projetos educativos.

Conforme tem sido reconhecido, à universidade cabe o papel não apenas de difundir o conhecimento existente, mas também de criar situações e gerar condições que permitam produzir novos conhecimentos (LEITE, 2009). E porque o mandato social desta instituição exige a sua intervenção na sociedade, espera-se que esse conhecimento produzido dê relevo a vivências interdisciplinares, combatendo práticas monodisciplinares e culturas individualistas permeadas pela hiperespecialização.

No entanto, para que isto aconteça, será preciso que as práticas docentes, na educação superior, sejam organizadas na lógica da interdisciplinaridade e concretizadas por meio de uma comunicação dialogante, capaz de propiciar a todos novas experiências numa multireferencialidade que, dentro do contexto aqui abordado, pode ser considerada a conjugação e aproximação de diversas disciplinas. Neste sentido, a multirefencialidade 
inscreve-se em um procedimento dialético, no qual o conhecimento, construído no âmbito das práticas docentes universitárias, é concebido em contínuo movimento, num constante ir e vir, o que possibilita uma inovação pedagógica e a construção do conhecimento de modo interdisciplinar.

Concluiu-se, portanto, que embora essa construção de conhecimento na docência universitária em Portugal e no Brasil se conduza no sentido da interdisciplinaridade, ainda apresenta algumas características de uma visão cartesiana e simplista. Por isso, torna-se relevante debater procedimentos capazes de promover práticas docentes universitárias na perspectiva de uma epistemologia da interdisciplinaridade, com base no diálogo, na parceria e no rigor científico.

\section{REFERÊNCIAS}

BARDIN, Laurence. Análise de conteúdo. Lisboa: Edições 70, 2014.

BOGDAN, Robert; BIKLEN, Sari. Investigação qualitativa em educação: uma introdução à teoria e aos métodos. Porto: Porto, 2010.

FAZENDA, Ivani. C. Arantes. Integração e interdisciplinaridade no ensino brasileiro: efetividade ou ideologia. 6. ed. São Paulo: Edições Loyola Jesuíta, 2011.

FAZENDA, Ivani C. Arantes. Interdisciplinaridade: um projeto em parceria. 4. ed. São Paulo: Loyola, 1999.

FAZENDA, Ivani C. Arantes. Interdisciplinaridade: história, teoria e pesquisa. Campinas: Papirus, 1994.

GUSDORF, Georges. O gato que anda sozinho. In: POMBO, Olga et al. (org.). Interdisciplinaridade: antologia. Porto: Campo das Letras, 2006. p. 19.

JANTSCH, Ari Paulo; BIANCHETTI, Lucidio (org.). Interdisciplinaridade para além da filosofia do sujeito. 9. ed. Petrópolis: Vozes, 2011.

KLEIN, Julie Thompson. Ensino Interdisciplinar: didática e teoria. In: FAZENDA, Ivani.

Didática e Interdisciplinaridade. 13. Ed. Campinas, SP: Papirus, 2008.

LEITE, Carlinda. "Prefácio" a SILVA, Maria de Fátima Gomes et al. (org.). Cultura,

Práticas Educativas, Currículo e Gênero: a tessitura de um olhar multidisciplinar. $1^{\mathrm{a}} \mathrm{ed}$. Recife: EDUPE, 2009.

LIMA, Débora Nascimento de; CASSIMIRO, Ana Carla Souza da Silva;

RABELO, Amanda Oliveira. Interdisciplinaridade no âmbito da educação infantil: uma revisão sistemática. Imagens da Educação, Maringá, v. 10, n.2, p.125-138, mai./ago., 2020. Disponível em: 
http://periodicos.uem.br/ojs/index.php/ImagensEduc/article/view/51225/751375150508 .Acesso em: 26 ago. 2020.

LIMA, Valderez; RAMOS, Maurivan. Percepções de interdisciplinaridade de professores de Ciências e Matemática: um Exercício de Análise Textual Discursiva. Revista Lusófona de Educação, Lisboa, v. 36, p. 163-177, 2017. Disponível em: https://revistas.ulusofona.pt/index.php/rleducacao/article/view/5997.pdf. Acesso em: 21 dez. 2019.

MORIN, Edgar. A cabeça bem-feita: repensar a reforma, reformar o pensamento. 4. ed. Rio de Janeiro: Bertrand Brasil, 2001.

MORIN, Edgar. Introdução ao pensamento complexo. 2. ed. Paris: Sociedade Astória, 1990.

OLIVEIRA, Maria Marly de. Como fazer pesquisa qualitativa. 4. ed. Petrópolis, Rio de Janeiro:Vozes, 2012.

PERIN, Conceição Solange Bution; MALAVASI, Silvana. A interdisciplinaridade no atual cenário educacional. Imagens da Educação, Maringá, v. 10, n.2, p. 139 - 151, mai./ago.,2020. Disponível em:

http://periodicos.uem.br/ojs/index.php/ImagensEduc/article/view/51240/751375150509 Acesso em: 25 ago. 2020.

ROGGERO, R. O Interdisciplinar na Universidade. In: O interdisciplinar - olhares contemporâneos. Ana Zahira Bassit (Org.). São Paulo: Factash, 2010, p. 139 -152

SANTANA, Iolanda; SILVA, Maria de Fátima Gomes. Práticas pedagógicas dos anos iniciais do ensino fundamental na perspectiva da interdisciplinaridade. Práxis Educacional, Vitória da Conquista, v. 12 n. 21, p. 181-206, jan./abr. 2016. Disponível em: http://periodicos2.uesb.br/index.php/praxis/article/view/866. Acesso em: 10 jun. 2020.

SILVA, Maria de Fátima Gomes. Para uma ressignificação da interdisciplinaridade na gestão dos currículos em Portugal e no Brasil. Lisboa: Fundação Calouste Gulbenkian, 2009.

SOUZA, Mariana Aranha de; BUSSOLOTTI, Juliana Marcondes; CUNHA, Virginia Mara Próspero da; FAZENDA, Ivani. Currículo e Interdisciplinaridade: o que dizem os estudantes de um mestrado profissional em educação. Imagens da Educação, Maringá, v. 10, n.2, p. 104-124, mai./ago., 2020. Disponível em: http://periodicos.uem.br/ojs/index.php/lmagensEduc/article/view/51219/751375150507. Acesso em: 27 ago. 2020 